\title{
PARA UNA DECLARACIÓN UNIVERSAL DE BIOÉTICA Y DERECHOS HUMANOS: UNA VISIÓN DE AMÉRICA LATINA
}

\author{
Juan Carlos Tealdi \\ Faculdad de Medicina de la Universidad de Buenos Aires, Buenos Aires, Argentina. \\ juancarlostealdi@uolsinectis.com.ar
}

Resumen: El respeto a la dignidad humana, a la igualdad de derechos y a la justicia son las únicas garantías de la paz en el mundo para el derecho de los derechos humanos, y por esto una bioética universal - una ética de la vida en términos universales - no puede sino conjugarse con los derechos humanos. Una visión liberal y pragmática de la ética puede traer como consecuencia la grave confusión entre los medios del desarrollo científico y tecnológico con los fines del desarrollo humano.

Palabras-clave: Bioética. Derechos humanos. Instrumentos normativos. América Latina.

\begin{abstract}
Respect for human dignity, equality of rights and justice are the only guarantees of peace in the world for the right to human rights. For that reason, a universal bioethics - an ethics of life in universal terms - can only conjugate itself with human rights. A liberal and pragmatic vision of ethics can bring as consequence a great confusion between the means of scientific and technologic development and the ends of human development.
\end{abstract}

Key words: Bioethics. Human rights. Normative instruments. Latin America.

\section{Bioética y Derechos Humanos}

La historia de la ética es, desde su origen, la historia de las ideas de dignidad,
igualdad y justicia. Cuando Sócrates dice, en el final del Gorgias, que el
mejor modo de vivir es el que consiste en vivir practicando la justicia, enuncia
el supuesto básico de la vida ética que sigue siendo, hoy, lo que sostiene una
bioética verdadera. El respeto a la dignidad humana, a la igualdad de derechos
y a la justicia son las únicas garantías de la paz en el mundo para el derecho
de los derechos humanos y por esto una bioética universal - una ética de la 
vida en términos universales - no puede sino conjugarse con los derechos humanos. Porque la bioética está destinada o bien a fortalecer y profundizar la moral mínima, que supone el respeto de los derechos humanos en tanto consenso prescriptivo universal, o bien a debilitar y confundir sus fines.

Pero, en modo alguno, la bioética y los derechos humanos pueden ser, como ha pretendido establecer una visión liberal y pragmática de la ética, campos disociados. Las consecuencias de dicha visión han sido confundir gravemente, por segunda vez en la historia, los medios del desarrollo científico y tecnológico con los fines del desarrollo humano. No obstante eso, fue en el derecho de los derechos humanos que la humanidad ha logrado definir, por primera vez, los contenidos básicos de una ética universal. La bioética ha de suponerse como un campo normativo dirigido a fortalecer y especialmente a profundizar esos contenidos en un ámbito de acción particularizado.

Por eso es que, a la hora de pensar en el mundo actual sobre una declaración universal de bioética, el título de la misma debería explicitar en forma clara la asociación entre la bioética como campo normativo particular en la atención y el cuidado de la vida y la salud, con los derechos humanos como campo normativo universal básico de obligaciones morales y jurídicas para todas las formas del vivir humano. Y así debería hablarse, en rigor, de una declaración universal de bioética y derechos humanos. En América Latina existe una importante tradición para que se pueda hacerlo.

\section{América Latina y los Derechos Humanos}

En abril de 1945, cuando se reunieron los delegados de cincuenta países en San Francisco para dar forma a la Carta de las Naciones Unidas aprobada el 24 de octubre de 1945, veinte de esos países eran latinoamericanos y configuraban el mayor bloque regional. Su papel fue determinante para alcanzar una concepción internacional de los derechos humanos. El 30 de abril de 1948 se proclamó la Declaración Americana de los Derechos y Deberes del Hombre - que fue la primera declaración de derechos humanos en su sentido estricto de compromiso de naciones -, y el 9 de diciembre de 1948 Charles Malik, portavoz de la Comisión de Derechos Humanos de las Naciones Unidas, reconoció el papel jugado por los países latinoamericanos en el logro de la Declaración Universal de Derechos Humanos que sería aprobada al siguiente día. Desde entonces, nuestra Región - Latinoamérica - ha sido muy activa tanto en el campo de los derechos humanos, como 
luego lo ha sido en la bioética. Y tiene, hoy, el deber de hacer oír su voz en el debate de un marco ético normativo mundial para practicar la justicia en la atención y el cuidado de la vida y la salud.

\section{Derechos Humanos, Problemas Bioéticos e Instrumentos Normativos}

En 1995, al hablar de la bioética y sus implicancias mundiales para la protección de los derechos humanos, la Unión Interparlamentaria recordó que la bioética deriva de la Declaración Universal de Derechos Humanos y reafirmó los acuerdos y convenciones internacionales sobre protección de los derechos humanos, así como del Código de Nuremberg y la Declaración de Helsinki de la Asociación Médica Mundial, como documentos fundamentales. Desde esta perspectiva, el preámbulo de una declaración universal de bioética y derechos humanos debe considerar, en primer lugar, los mayores antecedentes normativos internacionales y regionales en derechos humanos, los documentos normativos en problemas bioéticos de los organismos de Naciones Unidas, y los códigos de ética y documentos de bioética ejemplares en el nivel internacional; todos los cuales han ido construyendo, hasta la fecha, un valioso cuerpo normativo.

Sin embargo, y en segundo lugar, esa Declaración debería señalar con claridad cuáles son los problemas del mundo actual que hoy se revelan como una amenaza o vulneración de ese cuerpo de bioética y derechos humanos que es herencia de la humanidad y de sus luchas por un mundo más justo. Por último, y con la finalidad de ofrecer respuesta a esas amenazas, es que deberían trazarse los ejes mayores para la construcción conceptual de un nuevo instrumento normativo.

\section{El Cuerpo Normativo Heredado}

Debemos recordar los siguientes antecedentes:

- La Declaración Universal de Derechos Humanos y los instrumentos mayores de derechos humanos de las Naciones Unidas como son el Pacto Internacional de Derechos Civiles y Políticos; el Pacto Internacional de Derechos Económicos, Sociales y Culturales; la Convención para la Prevención y la Sanción del Delito de Genocidio; la Convención contra la Tortura y 
otros Tratos o Penas Crueles, Inhumanos o Degradantes; la Convención Internacional sobre la Eliminación de todas las Formas de Discriminación Racial; la Convención sobre la Eliminación de todas las Formas de Discriminación contra la Mujer; y la Convención sobre los Derechos del Niño;

- Los mayores instrumentos regionales como son la Declaración Americana de los Derechos y Deberes del Hombre; la Convención Americana sobre Derechos Humanos, o Pacto de San José de Costa Rica; la Convención Interamericana sobre Desaparición Forzada de Personas; la Carta Africana de Derechos Humanos y de los Pueblos; y la Convención sobre Derechos Humanos y Biomedicina del Consejo de Europa;

- Los documentos de bioética en organismos de Naciones Unidas como son la Declaración Universal sobre el Genoma Humano y los Derechos Humanos; y la Declaración Internacional sobre los Datos Genéticos Humanos de UNESCO;

- Los códigos de ética y documentos de bioética ejemplares en el nivel internacional como son el Código de Nuremberg, la Declaración de Ginebra, el Código Internacional de Ética Médica y la Declaración de Helsinki de la Asociación Médica Mundial.

\section{Los Problemas Bioéticos del Mundo Actual}

Después de casi seis décadas durante las cuales se ha ido construyendo trabajosamente ese cuerpo normativo de derechos humanos y bioética, el mundo de hoy resulta una nueva ofensa a la conciencia de la humanidad comparable tan sólo a la que sufrían los hombres y mujeres que trazaron el ideal común de la Declaración Universal de Derechos Humanos. Un mundo en el que la mayoría de los seres humanos ven vulnerados los derechos proclamados entonces porque hoy son prisioneros del temor y la miseria, del hambre y la desnutrición, de la guerra y la violencia, de la pobreza y la exclusión, de la falta de libertades y la destrucción del medio ambiente, de la manipulación y la explotación, de la tortura y el maltrato; bajo el común denominador de una realidad cada día más injusta en las diferencias entre las personas. En el campo particular de reflexión de la bioética que es el cuidado y la atención de la vida y la salud, todas esas calamidades se expresan simultáneamente porque la salud no llega a ser ni siquiera básicamente un estado de bienestar físico, mental y social; y porque el vivir expresa una realidad de masas humanas tan carenciadas que ni fuerzas tienen que les 
permitan la rebelión contra tanta opresión del cuerpo y el espíritu. La aparición de nuevas epidemias como el Sida (Aids) no ha hecho más que poner al descubierto en el modo más descarnado que supone la mortandad de poblaciones enteras, esa extrema vulnerabilidad en la que transcurre la vida de niños, mujeres, hombres y ancianos, cuyas características de humanidad parecen haber quedado reducidas a la forma de números y porcentajes.

\section{Dinámica de los Valores Éticos}

Por eso es que todo ese cuerpo normativo heredado debe ser recordado para reafirmarlo en una declaración universal de bioética y derechos humanos emanada de un organismo de las Naciones Unidas, pero no sólo nominalmente sino en toda la magnitud moral que la letra de cada documento supone. El artículo 3 de la Declaración Universal reconoce el derecho a la vida (y a la libertad y la seguridad) a partir del cual se han de reconocer otros derechos como el derecho a la salud.

Pero, lo que debe entenderse para una visión de la bioética auténticamente universal es que cada valor fundamental, como en este caso es el valor de la vida, se interrelaciona con otros valores que a su vez le dotan de significado. El valor de la vida en la bioética de los países industrializados se asocia muy frecuentemente al valor de la libertad en cuestiones tales como la eutanasia y el suicidio médicamente asistido, pero en la bioética de los países pobres el valor de la vida se asocia más estrechamente al valor de la seguridad o integridad física, mental y social, en cuestiones tales como la alimentación, la vivienda y el agua potable. El desconocimiento de esta dinámica de los valores éticos, según los contextos nacionales y regionales en los que se objetivan, sólo puede conducir a una visión reduccionista de la bioética que, como siempre sucede, quedará entonces significada por aquellos discursos que tienen mayor poder de expresión, que expresan mejor sus intereses, pero que no por ello expresan mayor progreso moral.

\section{El Desarrollo Científico y Tecnológico}

El mundo industrializado privilegia los derechos civiles y políticos porque sus sociedades tienen satisfechas para la población en general sus necesidades básicas. Y en ese sentido esos países se preocupan con mayor interés por 
una bioética centrada en el desarrollo científico y tecnológico. Pero los países y las regiones pobres reclaman con mayor énfasis los derechos económicos, sociales y culturales, porque en una región como América Latina el porcentaje de población en la pobreza, la indigencia y la exclusión es mayoría.

Y en este sentido nuestros países se preocupan con mayor interés por una bioética centrada en el derecho a la salud. Estas diferencias explican por qué en los países industrializados puede observarse a veces o bien, una asociación retórica entre bioética y derechos humanos o bien, una completa disociación en la que se niega a la salud como derecho, se pone en entredicho el concepto de dignidad humana para la bioética y se cuestiona el carácter absoluto, inalienable, universal y no negociable de los derechos humanos. Y estas diferencias también explican por qué para los países pobres la asociación efectiva entre bioética y derechos humanos resulta tan marcada ya que en una realidad donde está vulnerada la ética mínima de los derechos humanos es inimaginable la construcción de una bioética que no comience discutiendo los límites de la moralidad con la inmoralidad antes que las refinadas fronteras analíticas del lenguaje moral, con todo lo importante que éstas son.

Hoy se acepta en un sentido suficientemente amplio que la bioética se ha enfrentado desde su origen a los problemas de respeto de la dignidad humana en la atención y el cuidado de la vida y la salud; los problemas de justicia en los sistemas de atención de la salud pública; y los problemas del poderío y ambigüedad moral del desarrollo científico y tecnológico para la supervivencia de la especie humana y el bienestar de las personas. Por eso es que una noción de bioética que no exprese claramente la vinculación entre vulneración de los derechos humanos y problemas éticos de la vida y el vivir humanos; o que hable de 'progreso' o 'adelanto' científico-tecnológico sin considerar que la noción de 'adelanto' es controvertida en su significación ya que presupone un sentido evaluativo que a la luz de la falta de desarrollo humano en el mundo no puede ser sino cuestionable; una noción de bioética así -afirmamos- no es compatible con los desarrollos teóricos y prácticos que aún con sus diferencias en autores y países han caracterizado en modo amplio a lo que se entiende por bioética.

$\mathrm{Y}$ es por eso que al momento de pretender identificar los problemas bioéticos del mundo de hoy debemos dejar de lado entonces a la expresión "adelantos científicos y tecnológicos" para sustituirla por la expresión "desarrollo científico y tecnológico en el campo de la atención y el cuidado de la vida y la salud", porque de otro modo dejaríamos de ver los problemas éticos que emergen de la ambigüedad de este desarrollo. 
Sobre esta cuestión ya llamó la atención la Asamblea General de las Naciones Unidas en 1975 con su Declaración sobre el uso del progreso científico y tecnológico en los intereses de la paz y para el beneficio de la humanidad, advirtiendo sobre el peligro potencial que el progreso científico y tecnológico puede representar para los derechos civiles y políticos y para la dignidad humana y haciendo un llamado a los estados para prevenir consecuencias dañinas.

\section{Valores, Principios y Virtudes}

Toda fundamentación sistemática en ética debe dar cuenta del lugar que ocupan los valores, los principios y las virtudes éticas. A la hora de ordenar los supuestos fundamentales de una ética universal, deberían buscarse criterios de jerarquía axiológica en el orden del derecho de los derechos humanos y de acuerdo con ello hablar de "valores fundamentales", seguidos de "principios de aplicación" y "prácticas de respeto", para concluir con las "reglas de procedimiento". El derecho de los derechos humanos ha sabido identificar con toda lucidez los valores fundamentales de una ética universal en el respeto de la dignidad humana y la primacía de la persona, la igualdad de derechos y la libertad, la justicia, la fraternidad y la paz.

Una bioética universal no puede sino fundarse en los pilares axiológicos de estos valores. Pero el derecho de los derechos humanos también ha sabido identificar principios éticos básicos de aplicación en el derecho a la vida, el derecho a la identidad; el derecho a la no discriminación, el derecho a la integridad física, mental y social, el derecho a la atención de la salud, los derechos al bienestar y el desarrollo humano y el derecho a un orden social e internacional justo. Por eso es que una bioética universal que reconozca como marco básico al derecho de los derechos humanos no puede sino estar basada en estos principios.

Pero en una ética sistemática es necesario dar cuenta no sólo de los valores y principios que pretenden sustentarla sino también de las prácticas comprometidas con el respeto de esos valores y principios. Por eso es necesario que se señalen asimismo las virtudes o hábitos de conducta valiosos para hacer realidad aquellos principios y valores fundamentales ya que sin ellos toda enunciación termina siendo retórica. Y, finalmente, las reglas de procedimiento o aquellos enunciados morales más cercanos a los contextos de acción. 
Considerando la historia del derecho de los derechos humanos y la realidad del mundo de hoy, una declaración universal de bioética y derechos humanos, luego de sistematizar los valores y principios del cuerpo normativo heredado, debería poner especial atención en las prácticas de respeto de aquellos valores y principios y en las reglas de procedimiento que procuren hacerlos efectivos.

\section{El Derecho a la Identidad}

En ese marco que nos precede y que tenemos el deber de respetar todos los pueblos y personas sin distinción étnica o de idioma, de sexo o religión, de opinión política o condición social, a los países de América Latina nos interesa una declaración universal de bioética y derechos humanos que no deje de reconocer el derecho a la identidad individual, cultural y comunitaria. Desde la conquista y colonización esta Región tiene problemas con la identidad. El respeto de la diversidad cultural es una exigencia original que sigue teniendo plena actualidad. Las cuestiones de bioética que hoy tienen su punto de partida en el valor de la vida no pueden dejar de reconocer inmediatamente el valor de la identidad. En Argentina así lo hemos comprendido a la luz del drama de los niños nacidos en cautiverio durante la dictadura militar y cuya restitución ha sido emblemática en el cruce de los avances científicos y tecnológicos de la genética con el respeto de los derechos humanos. Por eso es que si debemos asegurar la vida de los individuos, tanto más debemos asegurar aquellas señas que le hacen ser quien es.

\section{El Derecho a la Salud Integral}

A los países de América Latina nos interesa asimismo que una declaración universal de bioética y derechos humanos defienda enfáticamente el contenido moral del derecho a una salud integral. Dos años antes de la proclamación de la Declaración Universal de los Derechos Humanos, cuando se constituyó la Organización Mundial de la Salud, se declaró que: “El disfrute del más alto nivel de salud que se pueda lograr es uno de los derechos fundamentales de cada ser humano, sin distinción de raza, religión, creencias políticas, condiciones sociales o económicas". El artículo 12 del Pacto Internacional de Derechos Económicos, Sociales y Culturales, dice: "1.Los Estados Partes 
en el presente Pacto reconocen el derecho de toda persona al disfrute del más alto nivel posible de salud física y mental".

Entre las medidas que deberían adoptar los Estados para asegurar la plena efectividad de este derecho, figuran la reducción de la mortinatalidad y de la mortalidad infantil y el sano desarrollo de los niños; el mejoramiento en todos sus aspectos de la higiene del trabajo y del medio ambiente; la prevención y el tratamiento de las enfermedades epidémicas, endémicas, profesionales y de otra índole y la lucha contra ellas; y la creación de condiciones que aseguren a todos asistencia médica y servicios médicos en caso de enfermedad. Hay que decir que una bioética que dedique su esfuerzo a fortalecer y profundizar este mandato moral con todos sus recursos teóricos y metodológicos, será sin duda alguna una bioética universal.

En el Informe 2003 del relator especial sobre salud de la Comisión de Derechos Humanos de las Naciones Unidas - Paul Hunt -, éste señala que cada año mueren en el mundo de enfermedades evitables 10 millones de niños - 30 mil cada día -; y 500 mil mujeres por enfermedades relacionadas con el embarazo y el parto. Esas muertes son 100 veces más elevadas en el Africa Sub-sahariana que en los países de la Organización para la Cooperación y el Desarrollo Económico. De los 45 millones de personas viviendo con VIH-Sida 39 millones pertenecen a países pobres. La tuberculosis causa 2 millones e muertes al año y la malaria 1 millón de ellas. De allí que ese relator se haya preocupado por los indicadores del derecho a la salud por diferencia con los indicadores de salud. Un indicador del derecho a la salud se diferencia porque se deriva de normas específicas para las políticas públicas en salud y porque su finalidad es el monitoreo del derecho. Pero el derecho a la salud no debe ser visto en forma aislada sino en relación a otros derechos humanos y libertades fundamentales, incluyendo la no discriminación y equidad.

Los indicadores del derecho a la salud pueden ser sistematizados en indicadores estructurales, de proceso y resultados. Un indicador estructural nos dirá por ejemplo si el Estado tiene un reconocimiento constitucional del derecho a la salud, si tiene un organismo de derechos humanos con el mandato de velar por el derecho a la salud, si ha adoptado una estrategia para reducir la mortalidad materna, si tiene una lista de medicamentos esenciales, y si tiene algún grupo de medicamentos con provisión garantizada por el Estado. Los indicadores de proceso nos brindarán información acerca del modo en que las políticas de salud se implementan, por ejemplo el porcentaje de mujeres atendidas durante su embarazo o el porcentaje de 
recién nacidos asistidos por personal especializado. Y los indicadores de resultados medirán los resultados obtenidos con la implementación de determinadas políticas, como por ejemplo el número de muertes maternas por 100 mil nacidos vivos o el número de muertes perinatales cada mil nacimientos. Queremos una bioética comprometida con las exigencias de cumplimiento de resultados para el progreso moral.

El Protocolo Adicional a la Convención Americana sobre Derechos Humanos, en materia de Derechos Económicos, Sociales y Culturales (Protocolo de San Salvador), consagra en su art. 10 el derecho a la salud y dispone que toda persona tiene derecho a "contar con servicios públicos básicos", entre los cuales deben encuadrarse los medicamentos esenciales definidos en el Programa de Acción sobre Medicamentos Esenciales de la OMS. El acceso a los medicamentos es uno de los mayores problemas de la bioética actual, como lo ha venido demostrando la fuerte disputa contra el párrafo 30 de la Declaración de Helsinki y la cuestión de los derechos sobre la propiedad intelectual y científica y el régimen de patentes en la industria farmacéutica ante la pandemia del Sida.

El Alto Comisionado por los Derechos Humanos de las Naciones Unidas se ha expedido sobre estas cuestiones, señalando que en la relación entre los derechos de propiedad intelectual y el acceso a los medicamentos debe reconocerse que dicho acceso constituye un derecho humano. Y aunque la aplicación y protección de derechos de propiedad puede ofrecer un entorno más seguro para la transferencia de tecnología a países en desarrollo, también puede constituir una base para establecer precios más altos de los medicamentos y transferencia de tecnología, que podrían restringir el acceso de los pobres. Los derechos de propiedad intelectual impiden muchas veces la distribución de bienes sociales a los países pobres que no pueden pagar los precios exigidos por los titulares de las patentes.

\section{El Derecho al Bienestar}

Finalmente, a los países de América Latina también nos interesa una declaración universal de bioética y derechos humanos que defienda el derecho al bienestar y al desarrollo humano. Al observar tantos males en nuestras poblaciones, no puede ser otro nuestro reclamo. En el primer párrafo del artículo 25 de la Declaración Universal, al establecer el derecho a un nivel de vida adecuado, se incluye la salud como uno de los factores que determinan ese 
nivel de vida, junto con el bienestar, la alimentación, el vestido, la vivienda, la asistencia médica y los servicios sociales necesarios. Pero América Latina es la región con mayores inequidades en el mundo y millones de personas viven en la pobreza, la indigencia y la exclusión social, mientras en modo creciente la riqueza se concentra cada día más en un pequeño porcentaje de personas. La ética se mide por sus fines y la finalidad primaria de quienes trabajamos en bioética y derechos humanos no puede ser otra que procurar el progreso moral que significa la justicia social. Si la historia de la ética desde su origen es la historia de las ideas de dignidad, igualdad y justicia; el supuesto básico para una bioética universal verdadera no puede ser otro que el vivir haciendo realidad en el mundo el valor de la justicia. 